\title{
Rethinking the terminology of mechanical circulatory support
}

\author{
Nader Moazami, MD, ${ }^{\mathrm{a}}$ and David Feldman, $\mathrm{MD}, \mathrm{PhD}^{\mathrm{b}}$
}

Mechanical circulatory support (MCS) has continued to grow to become one of the most important advanced therapy options for patients with end-stage heart failure. Continued improvements in survival outcomes, coupled with declining adverse events, hold the promise of advancing this therapy further into the mainstream of our daily practice. Guidelines are expected to be published by all major organizations, including the International Society for Heart and Lung Transplantation, American Heart Association and American College of Cardiology Task Force, and the Heart Failure Society of America. It is certainly foreseeable that the guidelines would recommend that any patient with end-stage heart failure that is refractory to continued medical treatment be evaluated by an expert team of cardiologist and surgeons for MCS. These changes will probably increase the number of referrals for this therapy. Continued advances in the field related to development of totally implantable pumps and improved battery life will make this therapy even more socially acceptable to patients. In the near future, MCS could potentially replace heart transplantation as the therapy of choice or the new criterion standard treatment for end-stage heart failure.

To keep up with this advancing field, our MCS terminology should evolve to accommodate the needs of the profession and also take into account the desires and the psychosocial and societal needs of the community in which we practice. The MCS lexicon is full of terms and abbreviations that are familiar to us in the field but are a foreign language to most physicians and patients alike. Terms such as bridge to transplant, bridge to recovery, bridge to decision, bridge to candidacy, and finally destination therapy are used routinely by those of us in this field. The terminology has become so ingrained in the field that all regulatory bodies, both governmental and nongovernmental agencies, are attached to these specific terms in planning the course of trials, determining reimbursement, and even approving the use of devices. More importantly, however, our patients often struggle with this complex terminology. In particular, one of the most inappropriate and bothersome terms has

\footnotetext{
From the Department of Cardiothoracic Surgery, ${ }^{\mathrm{a}}$ Minneapolis Heart Institute at Abbott Northwestern Hospital, Minneapolis, Minn; and the Department of Cardiology, ${ }^{\mathrm{b}}$ Georgia Institute of Technology, Atlanta, Ga.

Disclosures: Authors have nothing to disclose with regard to commercial support.

Received for publication March 5, 2012; revisions received March 26, 2012; accepted for publication April 5, 2012; available ahead of print May 3, 2012.

Address for reprints: Nader Moazami, MD, 920 E 28th St, Suite 610, Minneapolis, MN 55407 (E-mail: nader.moazami@allina.com).

J Thorac Cardiovasc Surg 2012;144:2-3

$0022-5223 / \$ 36.00$

Copyright (c) 2012 by The American Association for Thoracic Surgery doi:10.1016/j.jtcvs.2012.04.007
}

been destination therapy. Of the multiple definitions in the Merriam-Webster dictionary, ${ }^{1}$ the phrases that perhaps fit our context best define the word destination as follows, "Predetermined end, object, or use; ultimate design. The place set for the end of a journey, or to which something is sent; place or point aimed at.'

\section{DEVICES AS AN ALTERNATIVE TO TRANSPLANTATION}

The concept of using mechanical pumps as permanent cardiac replacements was among the visions of the early pioneers of mechanical circulatory support. In 1965, the National Heart, Lung and Blood Institute initiated a request for proposal for development of a total artificial heart. The first artificial heart was implanted in 1969 at the Texas Heart institute by Dr Denton Cooley, who used the pump developed by Dr Michael DeBakey and designed by Dr Domingo Liotta. This pump was implanted in a patient with postcardiotomy shock for a period of 3 days, until the patient received a transplant. The concept of a total mechanical heart pump made sense, because success with dialysis (the artificial kidney) had been already achieved. In addition, cardiac transplantation was clinically not well established because of the dismal results in its early days. Although pumps were easier to design in the laboratory and had been applied successfully in animal models, the human biologic interface proved to be a much more difficult challenge to many in the fields of engineering and industry. In addition, improved understanding of the immune system and better pharmacotherapy finally brought cardiac transplantation into the mainstream of medical therapy. Unfortunately, the high complication rate associated with the devices, along with the clinical success of heart transplantation, put a clinical end to the use of pumps as an alternative to transplantation.

The late 1980s to early 1990s witnessed a resurgence of this dream as success of using pulsatile left ventricular assist devices for stabilizing patients until successful transplantation became a reality. Once again, the excitement in this area led to proliferation of centers interested in advancing this technology. The high success rate eventually created a resurgence of interest in considering device therapy for patients who were not suitable candidates for heart transplantation. It appears that the term destination therapy was coined in during development of the landmark Randomized Evaluation of Mechanical Assistance for the Treatment of Congestive Heart Failure (REMATCH) trial, which eventually led in 2002 to the approval of the first device ever for patients with end-stage heart failure who 
failure of medical therapy. ${ }^{2}$ Subsequently, the HeartMate II trial was completed, and that device was approved for destination therapy in January of 2010. Data from the Interagency Registry for Mechanically Assisted Circulatory Support (INTERMACS) registry have demonstrated increases both in the number of centers implanting pumps and in the number of patients receiving pumps. ${ }^{3}$

\section{TERMINOLOGY OF MCS}

Currently, several trials are ongoing or are in various phases of negotiation with the Food and Drug Administration for the proper designation of devices and selection of patients to be enrolled in these trials. There continues to be an insistence on using the same old confusing jargon that has remained in our field. Although initially these terms were acceptable and allowed us to think about treatment options by putting patients in different categories, in the current era with its better pumps, this terminology is outdated and confusing to patients and referring physicians in the community. A recent patient seen in the office, whose device was implanted as destination therapy, was inquiring about a change in her status. Tearfully, she said, "When you are a bridge there is hope, destination feels like you hit the wall. Why don't you call it a journey, rather than a destination?"

It is time for our professional community to rethink the common terminology that we have gotten so used to and redirect it so that it is simplified for all patients, physicians, and regulatory and nonregulatory bodies involved with medical decisions and payment. An indication of pump placement for mechanical circulatory support of the failing heart refractory to medical therapy should be the sole need for considering long-term ventricular assist device placement. This community recognizes that a patient's status will be clarified with time. In fact, most of us recognize that those who recover should be considered for left ventricular assist device explantation and that future therapy aimed at adjunct pharmacologic and biologic interventions (such as stem cell therapy) could potentially make that an option for many patients regardless of our previously determined artificial initial designation of these patients. On the other hand, some patients will truly be candidates for transplantation whereas others will live with the pump as the designated therapy. For those who live with the pump, exchange is always an option if complications arise, and the first pump is not the "destination" implied by the current terminology. These principles are known and currently widely practiced among the MCS community of cardiologists and surgeons. It is now time to move them to the mainstream. We propose that a single designation for MCS indication be developed and put into practice, which would simply be end-stage heart failure refractory to medical therapy. The rest of the terms are no longer needed.

\section{References}

1. Merriam-Webster dictionary. Available at: http://www.merriam-webster.com. Accessed April 24, 2012

2. Rose EA, Moskowitz AJ, Packer M, Sollano JA, Williams DL, Tierney AR, et al The REMATCH trial: rationale, design, and end points. Randomized Evaluation of Mechanical Assistance for the Treatment of Congestive Heart Failure. Ann Thorac Surg. 1999;67:723-30.

3. Kirklin JK, Naftel DC, Kormos RL, Stevenson LW, Pagani FD, Miller MA, et al Third INTERMACS Annual Report: the evolution of destination therapy in the United States. J Heart Lung Transplant. 2011;30:115-23. 